\title{
Inovação em transformação
}

\section{GUILHERME ARY PLONSKI I}

\section{Concepção}

Inovação é a criação de novas realidades. Essa declaração singela realça características essenciais da inovação. Em primeiro lugar, ao ser criação ela é, ao mesmo tempo, o processo e o resultado de fazer existir algo que não havia e, por extensão, também de dar novo feitio ou utilidade a algo que já existia. Ao ser também entendida como processo a inovação deixa de ser percebida como fruto exclusivo de lampejos de inventividade ou engenhosidade, que certamente são bem-vindos e importantes. Ela passa a ser compreendida como um conjunto estruturado de ações ou operações visando a um resultado e, portanto, a inovação é propensa a ser estimulada, promovida e gerida. É, por conseguinte, um campo pluridisciplinar fértil para aplicação de conhecimentos e práticas de administração, direito, economia, engenharia, medicina e psicologia, entre outras.

Em segundo lugar, ao enfatizar como resultado do processo de criação a existência de novas realidades evidencia-se tanto a amplitude das possibilidades ensejadas pela percepção contemporânea da inovação como a complexidade da sua efetivação. Há apenas duas décadas a inovação era associada de forma quase exclusiva ao setor secundário da economia, principalmente ao lançamento de produtos industrializados intensivos em tecnologia, assim como a mudanças nos processos de fabricação. Hoje a inovação é objeto de desejo de todos os setores da economia, assim como também de outros segmentos da sociedade. Entre esses merecem destaque as diversas esferas e poderes dos governos, os quais estão em busca de inovações na gestão pública que lhes permitam atender aos anseios crescentes da cidadania, num contexto de constrição de recursos e retração acentuada da credibilidade dos governantes.

A complexidade do processo de inovação decorre precisamente das mutações inter-relacionadas que são necessárias para que uma nova proposição seja aceita e difundida. Em decorrência, a criação de novas realidades transformadoras pode levar um tempo bem mais longo do que se poderia esperar à primeira vista. Um exemplo é o prazo decorrido entre as primeiras trocas de mensagens por meio eletrônico entre pesquisadores, que ocorreram em meados da década de 1960, graças aos avanços da computação compartilhada, e a disseminação do correio eletrônico, que ocorreu apenas a partir de 1996. Essa inovação, hoje tão presente no cotidiano da população em geral, requereu uma combinação de fatores, alguns de cunho tecnológico e outros não. Entre eles estão a cessação de restrições legais que incidiam sobre o transporte de informação comercial na internet e a consolidação de protocolos de transmissão de mensagens, tais como o Simple Mail Transfer Protocol (SMTP) e o Post Office Protocol (POP). 
Outra ilustração eloquente do longo intervalo entre invenção e inovação é propiciada pela chamada Inteligência Artificial. De maneira simplificada, trata-se da busca de mimetização por equipamento e dispositivos de capacidades mentais humanas, entre as quais a interpretação de vastas quantidades de dados, a solução de problemas complexos e a aprendizagem. Hoje decantada pelo seu potencial de criar novas realidades, ela foi formulada já há seis décadas, notadamente no âmbito de um projeto de pesquisa que foi realizado nos idos de 1956 (Solomonoff, [20--]). Todavia, apenas nos dias atuais a Inteligência Artificial começa a frutificar, por exemplo, ao estar embarcada em veículos autônomos.

É certo que inovações de menor envergadura, em especial as denominadas inovações incrementais, podem gerar uma nova realidade, ainda que de ressonância limitada, em prazo significativamente menor do que os tempos indicados nos dois casos anteriormente expostos. Cabe observar que elas constituem uma parcela expressiva das inovações. Em verdade, o seu impacto cumulativo é tão grande quanto ou até mesmo maior do que o impacto das inovações ditas "radicais" e "revolucionárias" (Fagerberg, 2005). Essa constatação é contraintuitiva, pois as inovações radicais e revolucionárias obtêm uma exposição nos meios de comunicação bem maior do que a granjeada pelas inovações de natureza incremental.

É de esperar que as inovações incrementais estejam presentes, até mesmo em intensidade crescente, nas economias em desenvolvimento, ${ }^{1}$ o que de fato ocorre, por exemplo, na Índia e na China (Puga; Trefler, 2010). Menos previsível é a importância da inovação incremental também nas economias desenvolvidas. Estudo de megatendências publicado por uma consultora multinacional em gestão indica que as inovações incrementais têm potencial de, ao longo da corrente década, contribuir com cinco trilhões de dólares americanos para o Produto Interno Bruto global. Esse montante é cinco vezes superior à estimativa da contribuição combinada das novas plataformas tecnológicas, a saber, nanotecnologia, genômica, inteligência artificial, robótica e conectividade ubíqua (Bain, 2011).

A explicação dada pelos autores é a macrotendência "Tudo do mesmo, mas mais agradável" (no original, "Everything the same, but nicer"). Segundo esse lema, a inovação focaliza atualmente e continuará focalizando cada vez mais a criação de produtos sofisticados e serviços que substituem os que eram habitualmente adquiridos. Passa então a ser gerada uma variedade de produtos de nicho, e se formam condições para atribuir preços mais elevados a consumidores afluentes. Esse argumento é ilustrado no referido relatório pelo trivial café, que é apresentado como um produto de baixo conteúdo tecnológico, mas que foi incrementado para gerar maior valor econômico. Realmente, em nosso próprio meio somos testemunhas do surgimento recente das redes de cafés requintados, que se tornaram locais de vivência e convivência, assim como das máquinas de café elegantes para uso caseiro ou em escritórios, alimentadas por cápsulas de variados sabores, com pós de múltiplas origens geográficas. 
Inovações radicais e incrementais se adicionam e reforçam mutuamente no esforço de criar novas realidades. Veja-se o caso da bicicleta, artefato cuja versão pioneira data de julho de 1817 , portanto exatos duzentos anos antes da redação do presente artigo. Mudanças técnicas e de design incrementais sucessivas no artefato em si se associaram a alterações gradativas nos costumes da sociedade ${ }^{2}$ a reformulações no traçado das vias urbanas e à modernização tecnológica dos sistemas auxiliares, como os de controle do tráfego. Esse processo, por sua vez, "pegou carona" nos movimentos contemporâneos de exaltação da atividade física e de reconhecimento da importância de se mitigar as pegadas de carbono dos meios de transporte. É a convergência de todos esses fatores que explica por que as bicicletas, agora com o apelido carinhoso de "magrelas", puderam se tornar um instrumento tão popular de mobilidade urbana e lazer, que é utilizado praticamente por todos os segmentos de moradores.

A história da bicicleta mostra a importância da consideração do caráter sociotécnico do processo de inovação e a necessidade de confluência sistêmica de mutações em diversos campos para que se consiga efetivamente criar novas realidades. Essa constatação traz à arena da inovação as contribuições de um elenco de disciplinas adicionais às que foram nominadas anteriormente, tais como arquitetura, ciências sociais, comunicação, filosofia, geografia e história.

O envolvimento das ciências exatas e da natureza, bem como da matemática e das ciências da computação no processo de inovação é intenso, dado o seu elevado potencial de alavancá-lo pela utilização do conhecimento científico, cujo avanço é portentoso. Parcela significativa das atenções vem sendo concentrada, há décadas, aqui e em outras partes, na busca de formas de melhor articular os processos de pesquisa científica, desenvolvimento tecnológico e inovação. Avanços importantes vêm sendo registrados como, no estabelecimento de formatos jurídicos e institucionais que assegurem fluidez no compartilhamento de conhecimentos no âmbito da cooperação entre empresas, universidade e institutos de pesquisa. Mas é necessário sempre ter presente que a inovação é um processo multifacetado, em que a dimensão científico-tecnológica, quando presente, é apenas um dos aspectos, ainda que de relevância capital em numerosos casos.

Cabe explicar a cláusula "quando presente". Costumamos pensar no trio "ciência - tecnologia - inovação" como indissociável, em certa medida por razões que têm a ver com a configuração da estrutura organizacional do governo federal e decorrente modo de atuação. ${ }^{3}$ Em outras palavras, tendemos a enxergar a inovação como decorrência da descoberta científica, mediada pela transposição do novo conhecimento a uma ou mais tecnologias, protegidas ou não por mecanismos tais como patentes de invenção ou segredos industriais. Esse processo certamente ocorre e é da maior importância. Todavia, é preciso ter presente que novas e marcantes realidades também são criadas mediante inovações em que a ciência tem papel adjuvante. É, por exemplo, o caso de duas inovações 
que criaram novas realidades de enorme repercussão geopolítica internacional, ao transformarem um campo que moldou a sociedade global, o do comércio internacional: a instituição do seguro, no século XIV, e a utilização do contêiner, a partir de meados do século passado.

Às vezes novas realidades são criadas por inovações que poderiam ser qualificadas como prosaicas. Um exemplo local tocante é o conjunto articulado de inovações institucionais, organizacionais e socioeducacionais que permitiu ao Brasil atingir já em 2012 a meta estabelecida no Objetivo de Desenvolvimento do Milênio \#4, que trata da redução da mortalidade infantil, ou seja, três anos antes do prazo estabelecido no compromisso internacional patrocinado pela ONU. Segundo relatório do Fundo das Nações Unidas para a Infância (Unicef) a impressionante queda de $77 \%$ da taxa de mortalidade de menores de cinco anos no país entre 1990 e 2012 se deveu a uma combinação de inovações cuja ênfase passa longe da sofisticação tecnológica, a saber:

[...] a criação de um Sistema Único de Saúde com foco na atenção primária de saúde, melhoria no atendimento materno e ao recém-nascido e esforços para prestar assistência à saúde no nível comunitário, melhoria das condições sanitárias, aumento do conhecimento das mães, promoção do aleitamento materno, expansão da imunização e criação de iniciativas de proteção social como o programa de transferência de renda Bolsa Família. (Unicef, 2013)

Em síntese, a inovação não é um fenômeno uno, mas um gênero multíplice de iniciativas humanas. Essas iniciativas visam, de forma cada vez mais metódica, à criação de novas realidades. Ocorre que essas realidades atendem a determinados interesses. Assim, a concepção da inovação como um processo propositado suscita uma ampla gama de indagações fundamentais, entre as quais se destacam as seguintes:

- Quais são as partes interessadas ativas, e como explicitam os seus interesses na nova realidade que tencionam criar mediante alguma modalidade ou combinação de modalidades de inovação?

- Quais são as partes interessadas que se envolvem por uma determinada inovação por serem, ou ao menos por acreditarem ser, afetadas negativamente em seus interesses pela nova realidade gerada por uma determinada inovação?

- Como se arbitram os interesses conflitantes num processo de inovação, especialmente quando existe assimetria significativa de informação e de capacidade de organização entre as partes interessadas ativas e as afetadas por um processo de inovação?

- Como se compartilham os riscos inerentes a qualquer processo de inovação?

- Quem se apropria e como se distribuem os benefícios da inovação, se e quando ocorrerem? 
A abrangência e a magnitude dessas questões, bem como de outras perguntas afins são facilmente aquilatadas quando se examinam temas controversos, tais como os efeitos das inovações na quantidade e qualidade dos empregos e de outras formas de ocupação, na sustentabilidade ambiental do planeta e nas relações de poder internacionais ou no interior de uma sociedade nacional. Sem aprofundar esses e outros temas fundamentais, ressalta-se aqui apenas a necessidade de ter claro que, longe de constituir um fenômeno neutro e anódino, a inovação é um processo impregnado por valores e, como corolário, fortemente mobilizador.

\section{Evolução}

Não deixa de ser surpreendente a opinião francamente positiva acerca da inovação nos diversos estamentos da sociedade e, de forma geral, a sua adoção no imaginário popular. Numa nação crescentemente polarizada, é uma das raras matérias em que as posições são convergentes. Assim, com o beneplácito de todos os partidos, o Congresso Nacional tem aprovado legislações benéficas a essa causa, tendo inclusive introduzido a Inovação na Constituição Federal em fevereiro de 2015. ${ }^{4}$ Por sua vez, a imprensa nacional é quase unânime no apelo a mais Inovação para destravar o desenvolvimento e promover o crescimento da economia e do bem-estar; manifestações similares ocorrem nos meios de comunicação em outros países, independentemente do regime político em vigor. ${ }^{5}$

A comunidade empresarial avista na Inovação uma versão contemporânea do bordão "a salvação da lavoura". Alguns dirigentes chegam considerá-la uma espécie de panaceia, capaz de resolver problemas de diversas ordens de seus negócios - mercadológicos, tecnológicos, motivacionais, organizacionais e outros. Por sua vez, a opinião pública é atraída pelo apelo da inovação, mesmo sem muitas vezes compreender bem do que se trata. Essa mitificação talvez explique a atual proliferação do atributo de inovador na propaganda de uma variedade de produtos. Por exemplo, o que exatamente quer uma imobiliária dizer ao colocar o rótulo "prédio inovador" numa edificação feita para moradia da classe média (VivaReal, 2017)?

Essa quase unanimidade sugere que a inovação adquiriu valor intrínseco, mais além da sua natureza de processo instrumental cuja função é a criação de novas realidades. Essa aura é percebida como sendo capaz de "contagiar" com seus dons virtuosos os bens, serviços, pessoas, organizações e instituições que a praticam ou, ao menos, buscam associar a inovação à sua identidade. E, por via de consequência, a ausência ou mesmo a insuficiência de inovação num determinado ambiente é interpretada como sinal de que algo não vai bem.

Mas nem sempre foi assim.

Roger Bacon foi mestre da renomada Universidade de Oxford, onde os seus predicados de estudioso em vários campos fizeram-no ser conhecido como "doutor prodigioso" (em latim, lingua franca acadêmica da época, Doctor Mirabilis). Esses campos incluíam matemática, astronomia, óptica e alquimia. Foi 
um promotor vigoroso da ciência experimental e proponente de artefatos como máquinas voadoras, navios e carruagens motorizadas (Crowley, 2017). Também frade franciscano, o doutor Bacon foi preso pelos seus confrades, sob a acusação de inovações suspeitas.

Esse episódio é objeto de extensa discussão na literatura especializada, com uma das correntes propondo ser a condenação devida à conexão que Bacon fazia entre fenômenos celestiais deduzidos da doutrina astrológica e o advento do cristianismo (Sidelko, 1996). Seja como for, tratava-se de heresia, caracterizada pela expressão de pensamentos discrepantes dos preconizados pelas autoridades da Igreja católica da época. Essa instituição exercia forte ingerência na universidade inglesa durante as fases iniciais do seu desenvolvimento, influência que manteve até a Reforma protestante ${ }^{6}$ (Alexander; Alexander, 2011).

A desventura do doutor Bacon nos traz dois sinais importantes. O primeiro é que, diferentemente das informações que são frequentemente propaladas, inclusive por entidades oficiais, a inovação não é um ideia surgida no século XX, nem Joseph Schumpeter é o seu autor. ${ }^{7}$ De fato, a acusação de inovações suspeitas imputada ao frade professor da Universidade de Oxford data do século XIII. O segundo alerta é que a percepção do valor da inovação se alterou extremadamente - de motivo de condenação à prisão, como relatado, a razão de premiação, como atestam as dezenas, e quiçá centenas, de concursos de inovação anualmente organizados por diversos agentes em nosso país.

Esses alertas suscitam numerosas perguntas, três das quais serão tratadas no presente artigo:

- Em que contexto surgiu a ideia de inovação?

- Quando e por que a inovação passou por mudança drástica de valor aos olhos da sociedade?

- Qual será o provável status da ideia de inovação no futuro previsível?

As duas primeiras questões serão tratadas na presente seção, com ênfase para a segunda. A última será abordada na seção seguinte e conclusiva. A principal referência aqui utilizada para expor a trajetória convoluta da inovação, desde a origem desse termo e até os dias atuais, é a abrangente e erudita obra do professor canadense Benoît Godin, do Instituto Nacional de Pesquisa Científica da Universidade de Québec, que tem o título sugestivo "Inovação contestada" (Godin, 2015).

Esse autor identifica a utilização da ideia de inovação, mas ainda não com esse nome, já por filósofos clássicos gregos como Platão e Aristóteles, que dela se valeram para expressar o fenômeno da confrontação de leis e costumes estabelecidos mediante introdução de mudanças políticas. E data o termo latino para inovação $($ in + novo $)$ como tendo sido introduzido no século III ou IV da era civil. O significado então atribuído oscilava entre a renovação de algo tradicional e a introdução de algo efetivamente novo. ${ }^{8}$ 
No ambiente europeu dominado pela Igreja católica buscava-se assegurar a manutenção estrita da ordem, entendida como divinamente estabelecida. Destarte, qualquer desvio passava a ser combatido ferozmente, mesmo que se manifestasse em especificidades do pensamento ou em pormenores da liturgia. ${ }^{9}$ Nesse clima, a inovação adquiriu caráter marcadamente negativo por exalar heresia, o que explica a citada atribulação do mestre de Oxford. Importa ressaltar que esse caso permite iluminar uma realidade importante da época, a saber, que a inovação era praticada mesmo naqueles tempos e costumes a ela refratários. Mas isso deveria ocorrer de forma silente, pois seria imprudente dar publicidade a esse tipo de atuação, assim como arriscado vangloriar-se por ser inovador.

A resistência dos guardiões da ordem estabelecida só fez aumentar pela emergência do que entendiam ser inovações radicais de caráter subversivo. Destacam-se, na religião, a Reforma protestante, que enfatizava a liberdade individual; na política, as revoluções, que buscavam acabar com as monarquias absolutistas ou, pelo menos, debilitar o seu poder; e na vida do povo, as reformas sociais e econômicas, que passaram a ser propugnadas de forma estridente por movimentos socialistas.

Ainda segundo Godin, a percepção do valor da inovação mudou no século XIX quando, em paralelo à perspectiva tradicional, passou-se a produzir uma narrativa histórica alternativa, em que certas inovações anteriormente vistas como negativas passaram a ser descritas como tendo sido benéficas. Essa nova leitura estaria associada ao utilitarismo, uma corrente filosófica liberal inglesa que vinha então adquirindo importância. Cabe observar que, ao contrário do que o seu nome sugere, a métrica referencial do utilitarismo para valoração da moralidade de ações não era a utilidade em si, mas sim a sua contribuição para a felicidade coletiva. ${ }^{10}$

Importante fator adicional para a mudança da percepção sobre o valor da inovação foi a ideia iluminista de progresso, proposta no século XVIII, segundo a qual a condição humana pode ser aprimorada mediante utilização da razão e por avanços na ciência. Esse pensamento, que se consolidou a partir do século XIX, gerou as condições intelectuais para que a inovação passasse a ser compreendida como instrumento capaz de promover o progresso e, em decorrência, melhorar a condição humana. Essa é exatamente a principal razão atribuída por Godin à sua tese principal, que é a associação da mudança drástica do significado da inovação à emergência da modernidade. A valoração positiva da inovação passou a ser dominante conforme crescia a consciência de que ela era um meio eficaz para a sociedade viabilizar o atendimento de necessidades e objetivos humanos, que não se restringiam ao campo material.

Contribuiu para a transformação da inovação de indesejável a atraente a ideia-força da liberdade individual, anteriormente vista como heresia, a qual ideia alimentou a percepção positiva da inovação pela noção da livre iniciativa. Essa expressão contém outro elemento relevante para a construção do moderno entendimento de inovação - a iniciativa, ou seja, a valorização da ação prática 
por sobre a mera atitude contemplativa. Entre as diversas enunciações sedutoras dessa atitude está a conhecida recomendação para "passar da teoria à prática".

É nesse contexto intelectualmente transformado que ciência e inovação começaram gradualmente a se aproximar, mas ainda não mediadas pela tecnologia. Tal mediação apenas ocorreu a partir do século XX, quando se conformou a compreensão de processo abrangente referida no inicio do presente artigo. A literatura que trata da complexa busca de efetividade a esse processo, pela maior fluidez das conexões entre a ciência, a tecnologia e a inovação é extremamente vasta, incluindo o oferecimento de numerosos modelos inspiradores. Eles refletem a ansiedade das diversas partes interessadas na aceleração do processo de inovação, de forma a potencializar os benefícios auferíveis pela sociedade dos volumosos investimentos de talento humano e recursos financeiros na produção de conhecimentos científicos. Uma ilustração no campo das ciências da vida é a interessante formulação desse processo como translação "do laboratório ao leito" (no original inglês, from bench to bedside), lema da chamada Medicina Translacional. ${ }^{11}$

\section{Projeção}

O valor positivo que passou a ser atribuído à inovação a partir da era moderna não deve impedir-nos de reconhecer o seu caráter desviante. Pois o inovador (ou inovadora) típico é alguém que não se conforma com um ou mais aspectos - tecnológico, econômico, social, político, religioso ou outro da realidade vigente. E por isso decide enfrentar uma jornada incerta para alterá-la, correndo risco expressivo de não conseguir alcançar o intento, por numerosas razões de várias ordens.

$\mathrm{Na}$ feliz síntese formulada por Godin, na era moderna a inovação se tornou um termo secularizado para heresia. Ora, ninguém é intrinsecamente herético. Essa caracterização é atribuída a alguém por outrem, tipicamente alguma autoridade ortodoxa (Duby, 1990). A grande mudança, então, não ocorre no inovador, que continua sendo um desviante por: (i) ter uma opinião sobre como a realidade pode e deve ser que discrepa do que é aceito ou compreendido pela maioria das pessoas num certo momento; e (ii) lançar-se à aventura de buscar criar a nova realidade por ele vislumbrada como correta e possível. A grande mudança ocorre, portanto, nos outros, nos que são circunstantes dessa aventura. O herege religioso era malvisto pelos outros; o inovador, herege secular, passa gradativamente a ser bem-visto pela sociedade.

O reconhecimento da gradação mencionada é importante. Pois no seu percurso o inovador frequentemente tem que confrontar a ordem aceita e afrontar interesses sedimentados, inclusive no próprio meio que o engaja para inovar. ${ }^{12}$ Ademais, na arena competitiva as organizações se esforçam para barrar as inovações de concorrentes. De fato, parcela significativa das patentes de invenção tem caráter "defensivo”, ou seja, são depositadas ou adquiridas por organizações - geralmente empresas com fins econômicos, para impedir, ou pelo menos postergar, inovações nela apoiadas que "canibalizem" produtos do seu portfólio. ${ }^{13}$ 
Por sua vez, a postura da sociedade com relação ao inovador é sensível à cultura - entendida como conjunto dos valores, tradições e costumes vigentes num período específico. A materialização mais contundente das diferenças interculturais é notada no tratamento recebido pelo inovador quando não consegue realizar o seu intento de criar a realidade almejada. Especialmente quando esse fato implica a extinção de recursos alocados por terceiros a essa empreitada, utilizados pelo inovador com boa fé e responsabilidade.

Uma das diversas pesquisas sobre o tema do tratamento do fracasso em organizações de diversos países propõe a diferenciação entre culturas “identificatórias" e "não identificatórias”. Nessas há uma compartimentalização entre a iniciativa e o inovador que a enceta. Em decorrência, o fracasso é tomado simplesmente como uma ideia que não deu certo. Ademais, o fracasso é celebrado como oportunidade de aprendizagem. Já nas culturas identificatórias o fracasso é uma questão de grandes proporções. Perguntados sobre a quem atribuir a responsabilidade de fracasso numa iniciativa inovadora, se à pessoa ou à ideia, verificou-se que $72 \%$ dos holandeses a atribuíram à ideia, enquanto apenas $12 \%$ dos japoneses deram a mesma resposta (Trompenaars; Woolliams, 2011).

É evidente que a penalização pelo não atingimento de uma inovação pretendida inibe novas iniciativas. Isso afeta não apenas o inovador que fracassou, como também outros inovadores potenciais e entidades do ecossistema de inovação dispostas a estimular e promover a inovação. Um surpreendente tratamento inovador dessa questão crítica está sendo dado no Brasil pelo insuspeito Tribunal de Contas da União (TCU), consubstanciado no programa InovaTCU. A rationale do Tribunal repousa sobre três constatações: (i) que as inovações disruptivas frequentemente emanam de iniciativas de empresas nascentes (startups): (ii) que a taxa de fracasso desses novos empreendimentos é maior do que a de sucesso, mesmo em ecossistemas mais maduros do que o brasileiro; ${ }^{14}$ e (iii) que a inovação passou a ser missão do Estado, conforme disposto pela já aqui comentada Emenda Constitucional 85. A convergência dessas evidências gerou a consciência de que as prestações de contas de gestores públicos não poderiam ser apreciadas com os critérios utilizados naquela Corte para outros gastos públicos e para investimentos de menor risco. Em decorrência,

[...] o Programa de Inovação do Tribunal de Contas da União (InovaTCU) foi instituído, em janeiro de 2015, para fomentar o desenvolvimento de cultura de inovação no âmbito da instituição, por meio do estímulo, do apoio e do acompanhamento de iniciativas e práticas inovadoras nas atividades de controle externo e, também, na governança e na gestão do próprio Tribunal. (Brasil, s. d.)

A inovação é, ao mesmo tempo, uma ideia transformadora e uma ideia em transformação. Então qual será o provável status da ideia de inovação no futuro previsível? Oferecem-se sete projeções à guisa de estímulo ao diálogo: 
1. A extensa trajetória da ideia de inovação na história do mundo ocidental, a sua capacidade de metamorfose, pela qual assumiu novos significados positivos, e a sua valorização global sugerem que se trata de um conceito duradouro.

2. Será intensificada a expansão da ideia de inovação a campos diversos dos tradicionais, como os setores de média e baixa intensidade tecnológica e, com vigor, na administração pública e nas organizações sem finalidade econômica (Julnes; Gibson, 2016). Dessa forma, a inovação deve ser entendida como gênero, com espécies distintas, incluindo, sem a elas se limitar, a inovação tecnológica, inovação social, inovação educacional, inovação jurídica e inovação filosófica. $^{15}$

3. A ampliação do conceito de inovação será acompanhada de ações para inseri-la nas políticas públicas, dando-lhes maior efetividade (OECD, 2005). Dessa forma, em paralelo a políticas públicas para inovação serão estabelecidas políticas públicas pela inovação.

4. A percepção da ampla gama de efeitos da inovação estimulará a busca de formas de regulação que atenuem efeitos considerados negativos, sem refrear exageradamente a sua capacidade transformacional. Novas inovações serão desenvolvidas para mitigar os efeitos deletérios de inovações anteriores.

5. Serão impulsionadas associações simbióticas entre a inovação e outros movimentos, como os da sustentabilidade ambiental e do empreendedorismo. Em decorrência dessa, empresas nascentes inovadoras de alto crescimento serão objeto de estímulos crescentes do poder público, de investimentos do setor financeiro e de parcerias com empresas estabelecidas. Ao mesmo tempo, prosseguirá a diversificação dos ambientes de inovação, originalmente composto por incubadoras de empresas e parques tecnológicos, como evidencia o recente conceito abrangente de "áreas de inovação" (Nikina; Piqué; Sanz, 2016).

6. A inovação é sensível ao contexto. Em decorrência, serão fortalecidos os ecossistemas de inovação, e a articulação de movimentos com força suficiente para moldar favoravelmente esse contexto (Plonski, 2005). Exemplo recente e bem-sucedido dessa mobilização é a atuação conjunta de mais de 50 entidades dos segmentos acadêmico, empresarial e governamental no delineamento e convencimento que levou à promulgação do novo marco legal da ciência, tecnologia e inovação.

7. Caberá às universidades, além da sua missão tradicional de ensino, pesquisa e extensão, um papel adicional relevante: o de organizar intelectualmente o crescentemente complexo território da inovação e a multiplicidade de transformações por ela ensejadas. Para isso serão essenciais os ambientes que favorecem abordagens interdisciplinares, em particular os institutos de estudos avançados. 


\section{Notas}

1 Utiliza-se a classificação da Organização das Nações Unidas (ONU, 2014).

2 Bijker (1997) relata o caso da uma ciclista inglesa que, em 1898, levou à corte judicial o fato de não ter sido atendida em uma estalagem por ter substituído a saia comprida, indumentária esperada das mulheres à época, por um traje mais adequado ao ciclismo. Ela perdeu a causa.

$3 \mathrm{O}$ trio ciência - tecnologia - inovação é conjugado em diversos documentos reitores da atuação do governo federal no campo da Inovação, como a Estratégia Nacional de Ciência, Tecnologia e Inovação 2016-2019, publicada pelo (então) Ministério da Ciência, Tecnologia e Inovação, cujo lema é "Ciência, Tecnologia e Inovação para o Desenvolvimento Nacional".

4 A Emenda Constitucional 85 alterou diversos artigos da Constituição Federal incluindo os seguintes: (i) Art. 23, que trata da competência comum da União, dos Estados, do Distrito Federal e dos Municípios: acrescentou à competência de proporcionar os meios de acesso à cultura, à educação e à ciência também os meios de acesso à tecnologia, à pesquisa e à inovação; e (ii) Art. 218, por cuja nova redação o Estado promoverá e incentivará, além do desenvolvimento científico, a pesquisa e a capacitação tecnológicas, também a capacitação científica e a inovação.

5 Poucas vozes na chamada grande imprensa são discordantes ou, ao menos, acauteladoras. Um dos poucos brados nesse sentido é um artigo publicado no diário Financial Times, referência do mundo das grandes corporações transnacionais, poucas semanas após o colapso do banco de investimentos norte-americano Lehman Brothers, que foi o epítome da crise financeira global irrompida em 2007 (Crook, 2008). O articulista interpreta a crise financeira como fracasso da regulação, por ser "um sistema sobrecarregado pela inovação" (no original inglês, "a system overwhelmed by innovation").

6 Conforme os citados autores, a Reforma protestante apenas alterou quem ingeria na universidade, mantendo-se a forte influência externa.

7 Essa informação equivocada aparece, por exemplo, no sítio na Internet do Instituto Nacional de Metrologia, Qualidade e Tecnologia (Brasil, s. d.), uma autarquia federal que se autointitula "inovadora". Sua missão é "prover confiança à sociedade brasileira nas medições e nos produtos, através da metrologia e da avaliação da conformidade, promovendo a harmonização das relações de consumo, a inovação e a competitividade do País”. Indica a entidade que "o termo 'inovação' tem sua origem na obra 'Teoria do Desenvolvimento Econômico’, escrita por Joseph A. Schumpeter, e publicada originalmente em inglês no ano de 1912" (Brasil, 2017). Registra-se que esse notável economista e cientista político norte-americano, nascido no que hoje é a República Checa, foi um dos primeiros estudiosos a considerar as inovações tecnológicas como o motor do desenvolvimento capitalista.

8 Cabe observar que essa ambiguidade parece ecoar a característica dual do Novo Testamento, que pode ser considerado ao mesmo tempo como obra de continuidade e de novidade. Por um lado é continuidade do Antigo Testamento, com esse compondo as denominadas Escrituras Sagradas. Pelo outro é novidade, conforme sugere a designação "Evangelho", palavra de origem grega que significa "boa nova", que comparece no título dos seus primeiros quatro livros (o Novo Testamento é composto por 27 livros). Cabe lembrar que o período mencionado coincide com o processo histórico pelo qual o cristianismo se tornou a religião oficial do Império Romano e, como tal, 
fator determinante da História Ocidental por numerosos séculos, mesmo após o esfacelamento desse Império.

9 Ainda no século presente se mantém o cuidado com minúcias litúrgicas, como ilustra recente normativa do prefeito da Congregação para o Culto Divino e Disciplina dos Sacramentos, autoridade eclesiástica do Vaticano, publicada na imprensa, que reforça serem inválidas para a Eucaristia hóstias completamente sem glúten (Sarah, 2017).

10 O princípio enunciado pelo seu principal proponente - o filósofo, economista e jurista inglês Jeremy Bentham (1748-1832) é o de que a medida do certo e do errado deve ser a maior felicidade do maior número de pessoas. Ele tem a seguinte formulação no original: "By the principle of utility is meant that principle which approves or disapproves of every action whatsoever, according to the tendency which it appears to have to angment or diminish the happiness of the party whose interest is in question: or, what is the same thing in other words, to promote or to oppose that happiness" (Bentham, 1789).

11 Uma definição concisa de Medicina Translacional é “a descrição da transição da pesquisa in vitro e experimentação em animais para aplicações humanas" (Wehling, 2015, p.1).

12 As agruras do inovador não raramente se manifestam na própria organização que o emprega. É emblemático o caso do engenheiro Steven J. Sasson, recém-formado empregado pela conhecida empresa Eastman Kodak em 1973. Dois anos depois ele inventou a primeira câmera fotográfica digital. $\mathrm{O}$ artefato pesava $3,6 \mathrm{~kg}$ e a qualidade da imagem registrada era baixa (0,01 megapixels). A câmera digital foi patenteada pela Kodak em 1978, mas a empresa por ela não se interessou, por estar confortável com a sua posição de virtual monopolista do mercado fotográfico norte-americano baseado na tradicional tecnologia de filmes revelados. Em 2009 o engenheiro Sasson recebeu a mais elevada condecoração presidencial, a Medalha Nacional de Tecnologia e Inovação. Em 2012 a Kodak pediu proteção legal para evitar a falência iminente, pois tardou em perceber e aproveitar o potencial da inovação decorrente da invenção do seu próprio empregado (Estrin, 2015).

13 Em mesa da qual este autor participou, por ocasião da III Triple Helix International Conference, realizada em 2000 no Rio de Janeiro, o responsável pela propriedade intelectual da filial brasileira de uma grande empresa transnacional do setor de bens de consumo indicou que $85 \%$ do seu portfolio é de "patentes defensivas".

14 De acordo com a experiência da Fundação Ewing Marion Kauffmann, referência mundial no campo dos estudos sobre empreendedorismo, "New ventures are more likely to fail than they are to succeed"(Kauffman Foundation, 2017).

15 A inovação em filosofia não é fenômeno recente (Rutheford, 2007).

\section{Referências}

ALEXANDER, K. W.; ALEXANDER, K. Higher Education Law: Policy and Perspectives. New York: Routledge, 2011. p.61.

BAIN. The great eight trillion-dollar growth trends to 2020. New York: Bain \& Company, 2011. Disponível em: <https://www.sec.gov/Archives/edgar/ data/1534155/000153415516000067/ex1015bainbreif8macrotrendsr.pdf>. Acesso em: 9 jul. 2017. 
BENTHAM, J. An introduction to the Principles of Morals and Legislation. Oxford, Clarendon Press, 1789. Disponível em: <http://oll.libertyfund.org/titles/bentham-an-introduction-to-the-principles-of-morals-and-legislation>. Acesso em: 15 jul. 2017.

BIJKER, W. E. Of bicycles, bakelites, and bulbs: toward a theory of sociotechnical change. Cambridge: MIT Press, 1997. p.2.

BRASIL. Emenda constitucional n.85, de 26 de fevereiro de 2015. Altera e adiciona dispositivos na Constituição Federal para atualizar o tratamento das atividades de ciência, tecnologia e inovação. Diário Oficial [da República Federativa do Brasil], Brasília, DF, 3 mar. 2015. Seção 1, p.5. Disponível em: <https://www.jusbrasil.com.br/diarios/86911494/dou-secao-1-03-03-2015-pg-5?ref=next_button>. Acesso em: 12 jul. 2017.

Instituto Nacional de Metrologia, Qualidade e Tecnologia. A evolução do conceito de inovação. Rio de Janeiro: s. d. Disponível em: <http://inovacao.inmetro.gov. br/como-o-inmetro-ve-a-inovacao/>. Acesso em: 11 jul. 2017.

BRASIL. Ministério da Ciência, Tecnologia e Inovação. Estratégia Nacional de Ciência, Tecnologia e Inovação 2016-2019. Brasília, 2016.

BRASIL. Tribunal de Contas da União. Referencial Básico do Programa de Inovação. Brasília: s. d.. Disponível em: <file:///C:/Users/Ary/Downloads/Referencial\%20B_ sico\%20de\%20Inova_o\%20do\%20TCU.pdf>. Acesso em: 16 jul. 2017.

CROOK, C. A system overwhelmed by innovation. Financial Times, London, 13 out. 2008. Disponível em: <https://www.ft.com/content/741905d0-9857-11dd-ace3000077b07658?mhq5j=el >. Acesso em: 10 jul. 2017.

CROWLEY, T. Roger Bacon: English philosopher and scientist. Encyclopaedia Britannica, atualização em 9 mar. 2017. Disponível em: <https://www.britannica.com/ biography/Roger-Bacon>. Acesso em 11 jul. 2017.

DUBY, G. Heresias e sociedades na Europa pré-industrial, séculos XI-XVIII. In:

Idade Média, Idade dos Homens. São Paulo: Cia. das Letras, 1990. p.175-184.

ESTRIN, J. Kodak's First Digital Moment. The New York Times, New York, 12 ago. 2015. Disponível em: <https://lens.blogs.nytimes.com/2015/08/12/kodaks-first-digital-moment/?_r=l\#>. Acesso em: 16 jul. 2017.

FAGERBERG, J. Innovation: a guide to the literature. In: FAGERBERG, J.; MOWERY, D. C.; NELSON, R. (Ed.) The Oxford Handbook of innovation. Oxford: Oxford University Press, 2005. p.1-26.

GODIN, B. Innovation contested: the idea of innovation over the centuries. New York: Routledge, 2015.

JULNES, P. D. L.; GIBSON, E. Innovation in the Public and Nonprofit Sectors: A Public Solutions Handbook. New York: Routledge, 2016.

KAUFFMAN FOUNDATION. Startup Survival, Failure and Growth. Kansas, 2017. Disponível em: <http://www.kauffman.org/key-issues/startup-survival-failure-growth>. Acesso em: 16 jul. 2017.

NIKINA, A.; PIQUÉ, J.; SANZ, L. (Ed.) Areas of Innovation in a Global World: Concept and Practice. Malaga: International Association of Science Parks and Areas of Innovation, 2016. 
OECD. Governance of Innovation Systems. v.1: Synthesis report. Paris: Organisation for Economic Co-Operation and Development, 2005.

ONU. Country classification. New York: Organização das Nações Unidas, 2014. Disponível em: <http://www.un.org/en/development/desa/policy/wesp/wesp_ current/2014wesp_country_classification.pdf>. Acesso em: 9 jul. 2017.

PLONSKI, G.A. Bases para um movimento pela inovação tecnológica no Brasil. São Paulo em Perspectiva, São Paulo, v.19, n.1, jan./mar. 2005. Disponível em: <http:// www.scielo.br/scielo.php? script=sci_arttext\&pid $=$ S01 02-88392005000100002>. Acesso em: 16 jul. 2017.

PUGA, D.; TREFLER, R. Wake up and smell the ginseng: International trade and the rise of incremental innovation in low-wage countries. Journal of Development Economics, v.91, n.1, p.64-76, jan. 2010.

RUTHEFORD, D. Innovation and orthodoxy in early modern philosophy. In: (Ed.) The Cambridge Companion to Early Modern Philosophy. Cambridge: Cambridge University Press, 2007. p.11-38.

SARAH, R. Carta-circular aos Bispos sobre o pão e o vinho para a Eucaristia. Congregação para o Culto Divino e Disciplina dos Sacramentos, 15 jun. 2017. Disponível em: <http://www.vatican.va/roman_curia/congregations/ccdds/documents/rc_con_ ccdds_doc_20170615_lettera-su-pane-vino-eucaristia_po.html $>$. Acesso em: 15 jul. 2017.

SIDELKO, P. L. The condemnation of Roger Bacon. Journal of Medieval History, v.22, n.1, p.69-81, 1996. Disponível em: <http://www. tandfonline.com/doi/abs/10.1016/0304-4181\%2896\%2900009-7 ? needAccess $=$ true $\&$ journalCode $=$ rmed20>. Acesso em: 11 jul. 2017.

SOLOMONOFF, G. Ray Solomonoff and the Dartmouth Summer Research Project in Artificial Intelligence, 1956, [20--]. [s.1.: s.n.]. Disponível em: <http://raysolomonoff. com/dartmouth/dartray.pdf>. Acesso em: 9 jul. 2017.

TROMPENAARS, F.; WOOLLIAMS, P. Lost in translation. Harvard Business Review, Boston, abr. 2011. Disponível em: <https://hbr.org/2011/04/lost-in-translation>. Acesso em: 16 jul. 2017.

UNICEF. Cerca de 35 milhões de crianças menores de 5 anos estão sob risco se a meta de mortalidade na infância não for atingida. Nova York; Brasília: Fundo das Nações Unidas para a Infância, 13 set. 2013. Disponível em < https://www.unicef.org/brazil/pt/ media_26030.html>.Acesso em: 9 jul. 2017.

VIVAREAL. Apartamento com 2 Quartos à Venda, $62 \mathrm{~m}^{2}$ por R\$270.000. Disponível em: <https://www.vivareal.com.br/imovel/apartamento-2-quartos-scharlau-bairros-sao-leopoldo-62m2-venda-RS270000-id-82860235/>. Acesso em: 15 jul. 2017.

WEHLING, M. (Ed.) Principles of translational science in medicine: from bench to bedside. 2.ed. London: Academic Press, 2015. 
RESUMO - Inovação é a criação de novas realidades. A partir desse conceito singelo, o artigo elabora sobre a concepção da ideia de inovação enquanto resultado e respectivo processo, ilustrando a sua abrangência e a complexidade de efetivamente criar novas realidades. Mostra que a ideia de inovação não é fruto do século XX, como frequentemente suposto, mas remonta à Antiguidade. Analisa a transformação histórica da valoração da inovação, cuja inflexão de heresia condenável a aspiração generalizada se deu ao longo do século XIX. Finalmente, expõe sete projeções para a inovação no futuro previsível.

PALAVRAS-CHAVE: Inovação, Progresso, Heresia, Transformação.

ABSTRACT - Innovation is the creation of new realities. Building upon this simple concept, the article discusses the idea of innovation, presented as both a result and a process, and highlights its comprehensiveness and the complexity of effectively creating new realities. It shows that the idea of innovation did not appear for the first time in the $20^{\text {th }}$ century, as it is often assumed, but dates back to Antiquity. The article analyzes the historical transformation of innovation's value, which changed from a reprehensible heresy to a desirable feature during the $19^{\text {th }}$ century. Finally, seven innovation trends are projected for the foreseeable future.

KEYWORDS: Innovation, Progress, Heresy, Transformation.

Guilherme Ary Plonski é professor titular da Faculdade de Economia, Administração e Contabilidade e professor associado da Escola Politécnica, ambas da Universidade de São Paulo (USP). É também vice-diretor do Instituto de Estudos Avançados da USP (gestão 2016-2020) e coordenador científico do Núcleo de Política e Gestão Tecnológica da USP. @-plonski2@usp.br

Recebido em 17.7.2017 e aceito em 28.7.2017.

${ }^{\text {I }}$ Faculdade de Economia, Administração e Contabilidade, Universidade de São Paulo, São Paulo, São Paulo, Brasil. 